\title{
Utilização de medicamentos fitoterápicos e plantas medicinais em diferentes segmentos da sociedade
}

\section{Use of herbal and medicinal plants in different segments of society}

\author{
Claudia Sarmento Gadelha ${ }^{1}$; Vicente Maia Pinto Junior ${ }^{2}$; Kevia Katiucia Santos Bezerra ${ }^{3}$; Patricio Borges Maracajá ${ }^{4}$ \\ Débora S. S. Martins ${ }^{5}$
}

\begin{abstract}
Resumo: A utilização de plantas medicinais como medicina alternativa é uma pratica milenar, no entanto, a inserção de fitoterápicos é recente, porém, tem sido incentivado a sua prescrição pelo SUS. A Organização Mundial de Saúde, leva em consideração a cultura e a biodiversidade existentes no Brasil, tendo em vista a complexidade que envolve a fitoterapia, a Política Nacional de Planta Medicinal e Fitoterápico. Esta pesquisa teve como principal objetivo avaliar o uso de fitoterápicos e de plantas medicinais na saúde básica do município de Sousa-PB. Para isso foram aplicados formulários com pacientes/usuários e profissionais de saúde (Médicos e Enfermeiros), a respeito do uso, indicações, contra indicações dentre outros. A pesquisa foi realizada entre os meses de julho a outubro de 2014 . Em relação ao faixa etária $90 \%$ dos entrevistados possuem idade entre 22 e 59 anos, com relação à renda dos usuários $40 \%$ dos mesmos possuem uma renda de menos de $\mathrm{R} \$$ 1.000,00, já à indicação do uso de plantas medicinais 96,7\% dos usuários utilizam por indicação popular. Em relação as plantas mais usadas pelos pacientes foram citadas: Quebra pedra 58 citações, Hortelã 44, Aroeira 38, Babosa 32, Alecrim do nordeste 16 e unha de gato 10 citações, 58,4\% dos usuários acham excelente a ideia de plantas medicinais e fitoterápicos do SUS disponível para a comunidade, $90 \%$ dos profissionais de saúde consideram inserção da fitoterapia no SUS e principalmente nas UFS como avanço para a terapia comunitária, $88 \%$ dos profissionais de saúde relataram que os conhecimentos que possuem não são suficientes para uma orientação e/ou prescrição adequada e plantas medicinais ou de fitoterápicos, em relação a freqüência e recomendações que os profissionais de saúde prescrevem fitoterápicos foram antidepressivo, calmante com uma freqüência de 0,35, seguidos de tosse, gripe e sistema respiratório com 0,31 e mal estar gástrico com 0,21. Entretanto, de acordo com os dados encontrados na pesquisa, sugerem-se mais incentivos por partes do poder público, além, de capacitação aos profissionais de saúde para que os mesmos se sintam preparados para prescrever fitoterápicos.
\end{abstract}

Palavras chave: Medicina alternativa, SUS, profissionais de saúde.

Abstract: The use of medicinal plants as alternative medicine is an ancient practice, however, the inclusion of herbal medicines is recent, however, has been encouraged their prescription by SUS. The World Health Organization, takes into account the culture and the existing biodiversity in Brazil, in view of the complexity involved in herbal medicine, the National Policy on Medicinal Plant and Herbal. This research aimed to evaluate the use of herbal and medicinal plants in the basic health of the municipality of Sousa-PB. To this were applied forms with patients / users and health professionals (doctors and nurses), regarding the use, indications, contraindications among others. The survey was conducted between the months of July to October 2014. In relation to the age group $90 \%$ of respondents have aged between 22 and 59, in relation to income users $40 \%$ of them have an income of less than R \$1,000,00, as the indication of the use of medicinal plants $96.7 \%$ of users use a popular statement. Regarding the plants most used by patients were cited: Breaking stone 58 quotes, Mint 44, Aroeira 38, 32 Aloe, Rosemary Northeast 16 and cat's claw 10 citations. 58.4\% of users find the excellent idea of SUS medicinal plants and herbal medicines available to the community, $90 \%$ of health professionals consider insertion of herbal medicine in the SUS and especially in the UFS as an advance for the community therapy, $88 \%$ of professionals Health reported that the knowledge they have are not enough for an orientation and / or proper prescription and medicinal herbal plants or in relation to frequency and recommendations that herbal prescribing health professionals were antidepressant, soothing with a frequency of 0.35 , followed by cough, flu and respiratory system with 0.31 and 0.21 with gastric discomfort. However, according to the data found in the search, it is suggest more incentives for parts of the government, in addition, training for health professionals so that they feel prepared to prescribe herbal medicines.

Key words: Alternative Medicine, SUS, health professionals.

\footnotetext{
*Autor para correspondência

Recebido para publicação em 03/01/2015; aprovado em 25/04/2015

${ }^{1}$ Médica Reumatologista, Professora Universitária da Disciplina de Reumatologia (UFCG). E-mail: cgadel@hotmail.com

${ }^{2}$ Graduado em Administração de Empresas; E-mail: vicente-maia@hotmail.com

${ }^{3}$ Médica Ginecologista e Obstetra docente do curso de medicina pela UFCG-Cajazeiras-PB

${ }^{4}$ D. Sc. Prof. Associado IV. Curso de Pós graduação Stricto Sensu em Sistemas Agroindustriais do CCTA/UFCG. E-mail: patriciomaracaja@ gmail.com

${ }^{5}$ Graduada em Biomedicina, Faculdades Integradas de Patos, Patos-PB; suzany_89@hotmail.com.
} 


\section{INTRODUÇÃO}

O conhecimento das plantas como também o uso das mesmas como medicamento têm acompanhado o homem ao longo dos anos. No entanto, os primeiros sinais de desenvolvimento tecnológico, relegaram de certa forma ao esquecimento, a utilização das plantas medicinais. Entretanto, recentemente vem ocorrendo um retorno a essa utilização, ganhando espaço no mercado que havia sido dominado por produtos industrializados (MELO FILHO, 2014).

Atualmente existe um crescente interesse mundial por produtos advindos da biodiversidade e, nesse contexto, o Brasil se encontra em uma posição de destaque, sendo detentor de grande diversidade biológica, despontando com uma grande variedade de espécies vegetais com potencial medicinal.

A utilização de plantas medicinais pelo homem é relatada desde a pré-história. Na caatinga nordestina as plantas são amplamente utilizadas na medicina popular pelas comunidades locais. Estas comunidades possuem uma vasta farmacopéia natural, a grande maioria das plantas utilizadas é proveniente dos recursos vegetais encontrados nos ambientes naturais ocupados por estas populações, ou cultivados em ambientes de cultivo antrópico a exemplo de hortas e quintais (GOMES et al., 2007).

Varias espécies vegetais possuem propriedades terapêuticas, entretanto, as mesmas representam a principal matéria médica utilizada pelas chamadas medicinas tradicionais, em suas práticas terapêuticas, sendo a medicina popular a que utiliza o maior número de espécies diferentes. No entanto, o uso de plantas medicinais representa um fator importante para a manutenção das condições de saúde das pessoas (HAMILTON 2003; IBIAPINA, 2014).

A Organização Mundial de Saúde, leva em consideração a cultura e a biodiversidade existentes no Brasil, tendo em vista a complexidade que envolve a fitoterapia, e a Política Nacional de Plantas Medicinais e Fitoterápicos (PNPMF) que objetiva ampliar o acesso a plantas medicinais, fitoterápicos e serviços relacionados à fitoterapia, voltada para a segurança, eficácia, qualidade e integralidade da atenção à saúde dos brasileiros, além do desenvolvimento da cadeia produtiva e da indústria nacional (BRASIL 2006; MACHADO, et al., 2012; IBIAPINA, 2014).

Grande parcela dos Municípios brasileiros têm incorporado, nas duas últimas décadas, Programas de Fitoterapia na atenção básica de saúde objetivando desta maneira ampliar as opções terapêuticas e suprir carências medicamentosas de suas comunidades, com isso visa melhorar a atenção à saúde ofertada aos usuários, principalmente os da rede pública (SOUZA, et al., 2013)

Diante do exposto, a referida pesquisa objetivou avaliar o uso de medicamentos fitoterápicos e de plantas medicinais na saúde básica do município de Sousa PB, tanto por profissionais de saúde como por pacientes.

\section{MATERIAL E MÉTODOS}

O estudo foi desenvolvido mediante uma pesquisa de campo, de caráter descritivo com uma abordagem qualiquantitativa. Onde foi realizada pesquisa em literatura especifica e em seguida a aplicação dos formulários ao publico pesquisado.

\section{Caracterização da área em estudo}

O Município de Sousa localiza-se na mesorregião do Sertão Paraibano, microrregião de Sousa. A sede municipal, a 223 metros de altitude, tem sua posição geográfica determinada pelo paralelo de $6^{\circ} 45^{\prime} 39^{\prime \prime}$ de latitude sul em sua interseção com o Meridiano de $38^{\circ} 13^{\prime} 51^{\prime \prime}$ de longitude oeste (IDEME, 2000). O mesmo ocupa uma área de $762 \mathrm{Km} 2 \mathrm{e}$ uma população de 62.635 habitantes (IBGE, 2000). É limitado ao Norte pelos Municípios de Vieirópolis, Santa Cruz e Lastro; ao Sul por Nazarezinho e São José da Lagoa Tapada; a Leste por São Francisco e Aparecida, e a Oeste por São João do Rio do Peixe e Marizópolis.

A maior parte do território do Município está inserida em uma bacia de origem tectônica, a Bacia do Rio do Peixe, que compreende as formações Antenor Navarro, Sousa e Piranhas, de idade cretácea, preenchida por rochas sedimentares de idade mesozóica, resultando em um relevo predominantemente plano. Ocorrem ainda sedimentos recentes, formando as planícies fluviais dos Rios do Peixe e Piranhas.

Figura 1- Localização do município de Sousa PB

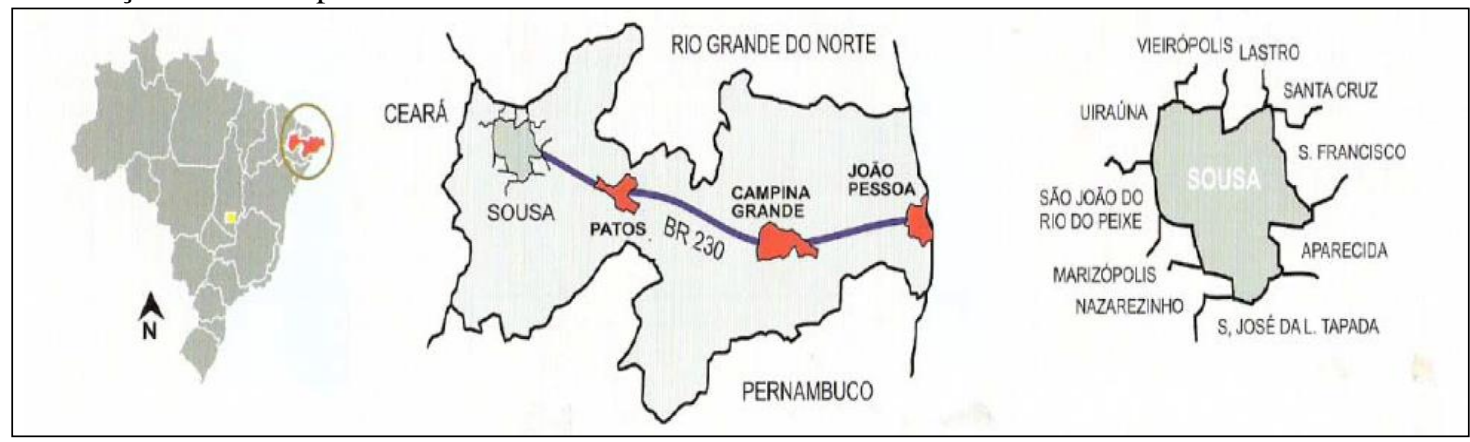

Fonte: Agenda Municipal - PMS 2005-2005

O município de Sousa, esta localizado no extremo Oeste do Estado da Paraíba, limitando-se a sul com Nazarezinho e São José da Lagoa Tapada, a Oeste com Marizópolis e São João do Rio Peixe, a Norte Vieiropólis, Lastro, Santa Cruz e a Leste São Francisco e Aparecida. Ocupa uma área de $761,7 \mathrm{~km}^{2}$, inserida na folha Sousa (SB
24- Z- A-V), escala 1: 100.000, editada pelo MINTER/SUDENE em 1972. Os limites do município podem ser observados no Mapa de Recursos Minerais do Estado da Paraíba, na escala 1:500.000, resultante do convênio CPRM/CDRM, publicado em 2002. A sede municipal 
apresenta uma altitude de $223 \mathrm{~m}$ e coordenadas geográficas de $38^{\circ} 13^{\prime} 51^{\prime}$ ' longitude oeste e $06^{\circ} 45^{\prime} 39^{\prime}$ ' de latitude sul.

\section{Aspectos Socioeconômicos}

O município foi criado pela lei $\mathrm{n}^{\circ} 28$ de 10 de Julho de 1854 e instalado na mesma data. De acordo com último censo do IBGE, a comunidade conta com uma população de 62.635 habitantes dos quais 30.116 São homens e 32.519 são mulheres. O número de alfabetizados com idade igual ou superior a 10 anos é de 38.194 o que corresponde a uma taxa de alfabetização de $74,2 \%$. A cidade conta com cerca de 15.365 domicílios particulares, destes 12.171 possuem esgotamento sanitário, 12.199 são atendidas pelo sistema estadual de abastecimento de água e um total de 10.392 com coleta de lixo. Na área de saúde o atendimento é prestado por 06(seis) hospitais e 32 unidades ambulatoriais. A educação conta com oitenta e três (83) estabelecimentos com Ensino Fundamental e de oito (8) estabelecimentos com Ensino Médio. O número de empresas cadastradas e atuantes com CNPJ é de 940. A agropecuária, indústria e comércio, constituem as principais atividades de ordem econômica da comunidade.

\section{População e amostragem}

Os informantes da pesquisa foram constituídos por profissionais da área de saúde (Médicos e enfermeiros), e usuários (pacientes). Foram aplicados 60 formulários por cada setor pesquisado, totalizando 120 formulários. Os formulários foram aplicados nos meses de julho a outubro de 2014.

\section{Procedimento para coleta de dados}

A princípio, foi realizado um levantamento dos profissionais de saúde e usuários que atuam nas unidades de saúde que foram pesquisadas, com o intuito de identificar o número de sujeitos e o horário de atendimento dos mesmos, de forma a facilitar o contato inicial e a posterior coleta de dados.

Os dados foram coletados com uso dos formulários I, II que foram aplicados sob a forma de entrevistas de maneira que será mantido o anonimato e a confidencialidade das informações prestadas.

Instrumentos de coleta dos dados instrumentos

Para coleta dos dados foram utilizados dois

Instrumento I: formulário abordando a fitoterápica como método terapêutico destinado aos profissionais de saúde (Médicos e Enfermeiros) (Apêndice A).

Instrumento II: formulário abordando o uso de plantas como método terapêutico destinado aos usuários do Programa de Saúde da Família (Apêndice B).

Análise dos dados

Os dados quantitativos foram coletados em formulários padronizados e tabulados em planilha eletrônica de dados (Microsoft Excel ${ }^{\circledR}$ 2003). Após sua coleta, os dados foram analisados quantitativamente através do modelo descritivo e apresentados em forma de gráficos e tabelas, visando desta maneira subsidiar a discussão dos resultados, foi promovido com respaldo na literatura pertinente ao tema em questão. Foi calculada a freqüência da amostra através da formula: $\mathrm{F}=\mathrm{N} / \mathrm{n}$ onde, $\underline{\mathrm{F}}$ é a freqüência a ser calculada, $\underline{\mathrm{N}}$ é a amostra total, ou seja, o número de entrevistados da seção e $\underline{n}$ é o número de vezes que um determinado dado foi citado durante a entrevista.

\section{RESULTADOS E DISCUSSÃO}

\section{Perfil da amostra entrevistada}

Os dados relacionados à faixa etária, sexo, e à ocupação, encontram-se relacionados nas tabelas 1,2 e 3 respectivamente.

Tabela 1- Faixa etária dos entrevistados, usuários e profissionais de saúde.

\begin{tabular}{ccccc} 
FAIXA ETÁRIA & $0-10$ & $11-21$ & $22-59$ & $\begin{array}{c}\text { Acima de } \\
60 \text { anos }\end{array}$ \\
\hline Usuários/pacientes & - & 01 & 54 & 05 \\
Profissionais de & - & - & 58 & 02 \\
Saúde & & & & \\
\hline
\end{tabular}

Em se tratando da idade dos entrevistados, os dados colhidos mostram que a maioria dos participantes pertence à faixa etária entre 22 e 59 anos $(\mathrm{n}=54)(90 \%)$ para usuários, enquanto que, apenas $(\mathrm{n}=5)$ possuem idade acima de 60 anos $(8,3 \%)$, e apenas $(n=1)$ paciente possui idade entre 11 e 21 anos (1,6\%), já para os profissionais de saúde (n = 58) estão na faixa etária entre 22 a 59 anos $(96,6 \%)$ e apenas $(n=2)(3,4 \%)$ possuem idade acima de 60 anos.

Em pesquisa realizada por Rodrigues e Andrade (2014) metade dos 75 entrevistados encontra-se na faixa etária de 29 a 56 anos e a principal atividade econômica é a prestação de serviços, com apenas $19 \%$ constituído por agricultores. O nível de escolaridade é muito baixo e apenas 10,7\% têm o Ensino Médio completo.

Ricardo (2009) lembra que a idade dos informantes e o contato com o meio rural favorecem o conhecimento sobre plantas medicinais, e dão como exemplo um informante de 54 anos que morou na zona rural durante 28 anos, ainda tendo contato regular com a região, e que, sozinho, citou 130 espécies de vários hábitos e usos. Ressaltou-se que o conhecimento acerca de plantas foi passado de geração a geração, não sendo detectadas, entre a população estudada, influências oriundas de meios de comunicação como o rádio e a televisão.

Os dados encontrados na presente pesquisa diferem dos dados colhidos por Bandeira (2014), onde os dados mostram que a maioria dos participantes pertencia à faixa etária entre 60 e 69 anos $(31,08 \%)$, seguida por aqueles que possuíam idades entre 50-59 anos $(24,42 \%)$. E, a faixa etária com o menor número de participante é aquela entre 80 e 89 (n = 2), representando $4,54 \%$ da amostra entrevistada. Em relação aos demais dados, 6,66\% dos entrevistados declararam ter idades entre 30 e 39 anos; e, 17,76\% afirmaram que tinham idades entre 40 e 49 anos.

Analisando-se os dados colhidos e apresentados na Tabela 2, verificou-se que dos 60 participantes da referida pesquisa, com relação aos usuários $17 \%$ pertenciam ao sexo masculino e $83 \%$, ao sexo feminino, já com relação aos profissionais de saúde $40 \%$ são do sexo masculino e $60 \%$ são do sexo feminino. 
Tabela 2- Distribuição dos participantes da pesquisa quanto ao sexo

\begin{tabular}{ccccc} 
SEXO & Usuários/pacientes & $\%$ & $\begin{array}{c}\text { Profissionais } \\
\text { de Saúde }\end{array}$ & $\%$ \\
\hline Masculino & 10 & 17 & 24 & 40 \\
Feminino & 50 & 83 & 36 & 60 \\
\hline
\end{tabular}

Marinho; Silva e Andrade (2011) promovendo um levantamento etnobotânico de plantas medicinais em área de caatinga no município de São José de Espinharas, Estado da Paraíba, entrevistou uma amostra constituída por homens e mulheres em percentagens iguais a $50 \%$, fato que, em muito pouco diverge do perfil da amostra entrevistada nesta pesquisa.

Porem em pesquisa realizada por Bandeira (2014) na $14^{\mathrm{a}}$ região administrativa da EMATER-PB, analisando etnoconhecimento e a utilização de plantas medicinais verificou resultados diferentes onde $60 \%$ dos participantes pertenciam ao sexo masculino e $40 \%$ ao sexo feminino, distribuídos nos municípios (Cajazeirinhas, Condado, Coremas, Lagoa, Paulista, Pombal, São Betinho, São Domingos e Vista Serrana), sediada na cidade de Pombal.

No que diz respeito à atividade dos entrevistados, os usuários responderam que $(\mathrm{n}=9) 12 \%$, não possuem ocupação, $(\mathrm{n}=2) 5 \%$, são aposentados, $(\mathrm{n}=3) 5 \%$ recebem auxilio doença, $(\mathrm{n}=24) 41 \%$ estão empregados e quem desenvolve outras atividades não informadas na pesquisa são $(\mathrm{n}=22)$ o que representa $37 \%$, já com relação ao profissionais de saúde $(\mathrm{n}=58)$ do entrevistados, ou seja, 97\% possuem vinculo empregatício e apenas $(\mathrm{n}=2) 3 \%$ desenvolvem outras atividades.

Tabela 3 - Distribuição dos participantes da pesquisa quanto ao exercício da atividade profissional

\begin{tabular}{ccccc}
$\begin{array}{c}\text { Exercício da } \\
\text { atividade } \\
\text { profissional }\end{array}$ & $\begin{array}{c}\text { Usuários/ } \\
\text { pacientes }\end{array}$ & $\%$ & $\begin{array}{c}\text { Profissionais } \\
\text { de } \\
\text { Saúde }\end{array}$ & $\%$ \\
\hline $\begin{array}{c}\text { Sem ocupação } \\
\text { Aposentado }\end{array}$ & 09 & 12 & - & - \\
$\begin{array}{c}\text { Recebe auxilio } \\
\text { doença }\end{array}$ & 03 & 05 & - & - \\
$\begin{array}{c}\text { Empregado } \\
\text { Desempregad } \\
\text { o s/ auxilio } \\
\text { doença }\end{array}$ & 24 & 41 & 58 & 97 \\
Outro & - & - & - & - \\
\hline
\end{tabular}

Melo Filho (2014) comenta que sempre existe uma grande correlação direta entre a ocupação do indivíduo e sua condição socioeconômica. Assim, nas comunidades rurais do interior do Nordeste e até mesmo nas pequenas cidades, a agricultura é ainda a atividade que dá ocupação à maioria da população. No entanto em pesquisa realizada pelo citado autor em comunidade rurais do município de Catolé do Rocha, como também na zona urbana e levando em consideração as particularidades que caracterizam a região semiárida, pode-se constatar que a maioria da amostra entrevistada possuía um baixo poder aquisitivo, visto que vivia quase que exclusivamente da agricultura familiar, justificando-se pela localização geográfica além da vocação agropecuária da região.
Guerra et al. (2010), em pesquisa realizada na comunidade rural Moacir Lucena, no município de Apodi$\mathrm{RN}$, foi composta, em sua grande maioria, por $75 \%$ de agricultores, dados esses que diferem dos apresentados nessa pesquisa, visto que, a pesquisa foi realizada na zona rural.

Analisando-se os dados colhidos e apresentados na Tabela 4, verifica-se que dos 60 participantes da presente pesquisa usuários, $(\mathrm{n}=4) 7 \%$ não sabe ler, $(\mathrm{n}=12) 20 \%$ possuem o Ensino Fundamental 1 incompleto, $(\mathrm{n}=4) 7 \%$ possuem o Ensino Fundamental 1 completo, $(\mathrm{n}=3) 5 \%$ possuem o ensino Médio incompleto, $(\mathrm{n}=17) 28 \%$ possuem o Ensino Médio completo, $(\mathrm{n}=7) 11 \%$ possuem Ensino Superior incompleto, $(\mathrm{n}=8) 13 \%$ possuem o Ensino Superior completo, $(\mathrm{n}=1) 2 \%$ possui Curso Técnico Profissionalizante, $(\mathrm{n}=3) 5 \%$ possuem Especialização e $(\mathrm{n}=$ 1) $2 \%$ possui Mestrado. Com relação aos profissionais de saúde $(\mathrm{n}=32) 53 \%$ possuem Curso Superior completo, $(\mathrm{n}=$ 27) $45 \%$ são Especialistas e $(n=1) 2 \%$ possuem Mestrado.

Germano et al., (2008), Afirmam que o acesso restrito à educação dificulta a compreensão das mensagens educativas, principalmente, no que diz respeito à saúde e a necessidade de mudanças de hábitos de vida. E que o grau de instrução é fator que incide diretamente na compreensão das orientações que são repassadas à sociedade.

No entanto, Melo Filho (2014) relata que a escolaridade é um indicador socioeconômico que facilita o trabalho da prevenção de algumas doenças, bem como à melhoria da qualidade de vida de uma população.

Tabela 4 - Distribuição dos participantes da pesquisa quanto ao grau de instrução

\begin{tabular}{|c|c|c|c|c|}
\hline GRAU DE INSTRUÇÃO & $\begin{array}{l}\text { Usuário/ } \\
\text { pacientes }\end{array}$ & $\%$ & $\begin{array}{c}\text { Profissionais } \\
\text { de Saúde }\end{array}$ & $\%$ \\
\hline Não sabe ler & 04 & 7 & - & - \\
\hline $\begin{array}{l}\text { Ensino Fundamental I } \\
\text { (incompleto) }\end{array}$ & 12 & 20 & - & - \\
\hline $\begin{array}{l}\text { Ensino Fundamental I } \\
\text { (completo) }\end{array}$ & 04 & 7 & - & - \\
\hline $\begin{array}{l}\text { Ensino } \\
\text { (incompleto) }\end{array}$ & 03 & 5 & - & - \\
\hline Ensino Médio (completo) & 17 & 28 & - & - \\
\hline Superior (incompleto) & 07 & 11 & - & - \\
\hline Superior (completo) & 08 & 13 & 32 & 53 \\
\hline $\begin{array}{l}\text { Curso Técnico } \\
\text { Profissionalizante }\end{array}$ & 01 & 2 & - & - \\
\hline Especialista & 03 & 5 & 27 & 45 \\
\hline Mestrado & 01 & 2 & 01 & 2 \\
\hline Doutorado & - & - & - & - \\
\hline TOTAL & 60 & 100 & 60 & 100 \\
\hline
\end{tabular}

Guizardi e Pinheiro (2008), estudando a experiência de farmácias fitoterápicas comunitárias em Vila Velha e Vitória, ES, mostram que apesar da grande proporção de pessoas com Ensino Fundamental completo ou incompleto, as atividades desenvolvidas tinham como premissa sistematizar e coletivizar o saber popular sobre plantas medicinais. No entanto, são relatados expressivos usos e conhecimentos sobre plantas medicinais, sugerindo que além da escolaridade não ser um fator determinante desses aspectos, são questões aprendidas e compartilhadas no meio do povo; um saber oriundo de experiências populares que se 
contrapõe, dessa forma, à lógica biomédica que centraliza o conhecimento e poder de decisão no médico.

Tabela 5 - Distribuição dos participantes da pesquisa quanto ao estado civil

\begin{tabular}{c|c|c|c|c} 
ESTADO CIVIL & $\begin{array}{c}\text { Usuários/ } \\
\text { pacientes }\end{array}$ & $\%$ & $\begin{array}{c}\text { Profissionais } \\
\text { de Saúde }\end{array}$ & $\%$ \\
\hline Solteiro & 07 & 11 & 15 & 25 \\
Casado & 42 & 70 & 30 & 50 \\
Namorando & 01 & 2 & 10 & 17 \\
Separado/divorciado & 04 & 7 & 02 & 3 \\
União estável & 01 & 2 & 03 & 5 \\
Viúvo & 05 & 8 & - & - \\
TOTAL & 60 & 100 & 60 & 100 \\
\hline
\end{tabular}

De acordo com os dados contidos na Tabela 5, verifica-se que o estado civil dos pacientes entrevistados, $(\mathrm{n}=$ 7) $11 \%$ são solteiros, $(\mathrm{n}=42) 70$ são casados, $(\mathrm{n}=1) 2 \%$ está namorando, $(\mathrm{n}=4) 7 \%$ são separado/divorciado, $(\mathrm{n}=1) 2 \%$ vivem em união estável e $(n=5) 8 \%$ são viúvos, já para os profissionais de saúde $(\mathrm{n}=15) 25 \%$ dos mesmos são solteiros, $(\mathrm{n}=30) 50 \%$ são casados, $(\mathrm{n}=10) 17 \%$ apenas namoram, $(\mathrm{n}=2) 3 \%$ são seprados/divorciados e $(\mathrm{n}=3) 5 \%$ vivem em uma união estável.

Analisando-se os dados colhidos e apresentados na Tabela 6 com relação à raça dos entrevistados, verificou-se que $(\mathrm{n}=30) 50 \%$ dos usuários entrevistados são brancos, $(\mathrm{n}=$ 4) $7 \%$ são negros, $(n=20) 33 \%$ são morenos e $(n=6) 10 \%$ são pardo/indígena, já para profissionais de saúde $(\mathrm{n}=36)$ $60 \%$ são brancos, $(\mathrm{n}=18) 30 \%$ são morenos, e $(\mathrm{n}=6) 10 \%$ são pardo/indígena.

Tabela 6 - Distribuição dos participantes da pesquisa quanto à cor/raça

\begin{tabular}{c|c|c|c|c} 
RAÇA & $\begin{array}{c}\text { Usuários/ } \\
\text { Pacientes }\end{array}$ & $\%$ & $\begin{array}{c}\text { Profissionais } \\
\text { de Saúde }\end{array}$ & $\%$ \\
\hline Branco & 30 & 50 & 36 & 60 \\
Amarelo/ & - & - & - & - \\
Oriental & & & & - \\
Negro & 04 & 7 & - & 30 \\
Moreno & 20 & 33 & 18 & 10 \\
Pardo/indígena & 06 & 10 & 06 & - \\
Outro & - & - & - & 100 \\
TOTAL & 60 & 100 & 60 & \\
\hline
\end{tabular}

A análise dos dados apresentados na Tabela 7, nos mostra a religião que cada participante da pesquisa pratica, no entanto, para os usuários $(\mathrm{n}=48) 80 \%$ dos mesmos são católicos, seguidos por $(n=2) 3 \%$ espiritas, $(n=10) 15 \%$ evangélicos, já com relação aos profissionais de saúde (n = 43) $71 \%$ são católicos, $(\mathrm{n}=15) 25 \%$ são evangélicos, $(\mathrm{n}=1)$ $2 \%$ são ateus e $(n=1) 2 \%$ pertencem a outras crenças. As plantas medicinais são comuns nas comunidades quilombolas e indígenas.
Tabela 7 - Distribuição dos participantes da pesquisa quanto à religião

\begin{tabular}{c|c|c|c|c} 
RELIGIÃO & $\begin{array}{c}\text { Usuários/ } \\
\text { pacientes }\end{array}$ & $\%$ & $\begin{array}{c}\text { Profissionais } \\
\text { de Saúde }\end{array}$ & $\%$ \\
\hline Católico & 48 & 80 & 43 & 71 \\
Espírita & 02 & 03 & - & - \\
Evangélico/protestante & 10 & 17 & 15 & 25 \\
Ateu & - & & 01 & 2 \\
Outras crenças & - & & 01 & 2 \\
TOTAL & 60 & 100 & 60 & 100 \\
\hline
\end{tabular}

De acordo com a análise dos dados relacionados à renda dos usuários/pacientes demonstrado na Figura 2, $(\mathrm{n}=$ 24) $40 \%$ dos entrevistados possuem renda abaixo de $\mathrm{R} \$$ $1.000,00$, já $(n=19) 32 \%$ possuem renda entre $R \$ 1.000,00$ e $\mathrm{R} \$ 1.500,00$ e $(\mathrm{n}=17) 28 \%$ possuem uma renda acima de $\mathrm{R} \$$ $1.500,00$.

Figura 2 - Distribuição da renda dos participantes da pesquisa

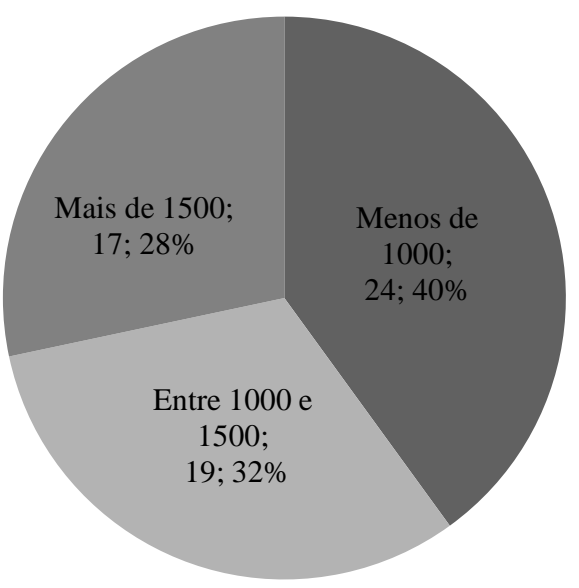

Atualmente, apesar do sistema de saúde oficial ser gratuito e estender-se à zona rural, ele não conseguem atender de forma adequada à demanda desta população, que também não tem poder aquisitivo suficiente para pagar diretamente um profissional de saúde (PILLA, et al., 2006). Além disso, medicamentos industrializados são caros e as pessoas se rendem à facilidade de se obter plantas medicinais, que muitas vezes são cultivadas nos quintais de suas casas (PILLA, et al., 2006). Queiroz (1993) realizando uma análise mais ampla, afirma que fatores gerais, tais como as condições de produção da oferta, o padrão de distribuição de renda, as políticas governamentais e a pertinência a classes e estratos sociais, imprimem uma influência fundamental na organização do consumo.

Um estudo desenvolvido pelo próprio Ministério da Saúde (BRASIL, 2005), mostra que a utilização das plantas medicinais, tanto no tratamento das doenças que afetam o ser humano como aquelas que acometem os animais, é uma prática mais presente entre as populações de baixo poder aquisitivo, sendo essa utilização justificada por diversos fatores, a exemplo do alto custo dos medicamentos sintéticos e da dificuldade de acesso aos serviços de saúde, bem como de sanidade animal. 
De acordo com a referida pesquisas como mostra a Figura 3, quando os participantes usuários/pacientes foram indagados sobre o tratamento com plantas medicinais por quem foi indicado, $(n=58) 96,7 \%$ responderam que fazem uso de plantas medicinais rotineiramente e apenas $(n=2)$
$3,3 \%$ responderam que fazem uso de plantas medicinais indicados por médicos, isso demonstra que o uso de fitoterápicos indicados por médicos na comunidade pesquisada ainda é muito pequena.

Figura 3 - Distribuição da amostra quanto à indicação do uso de plantas medicinal ou fototerápico.

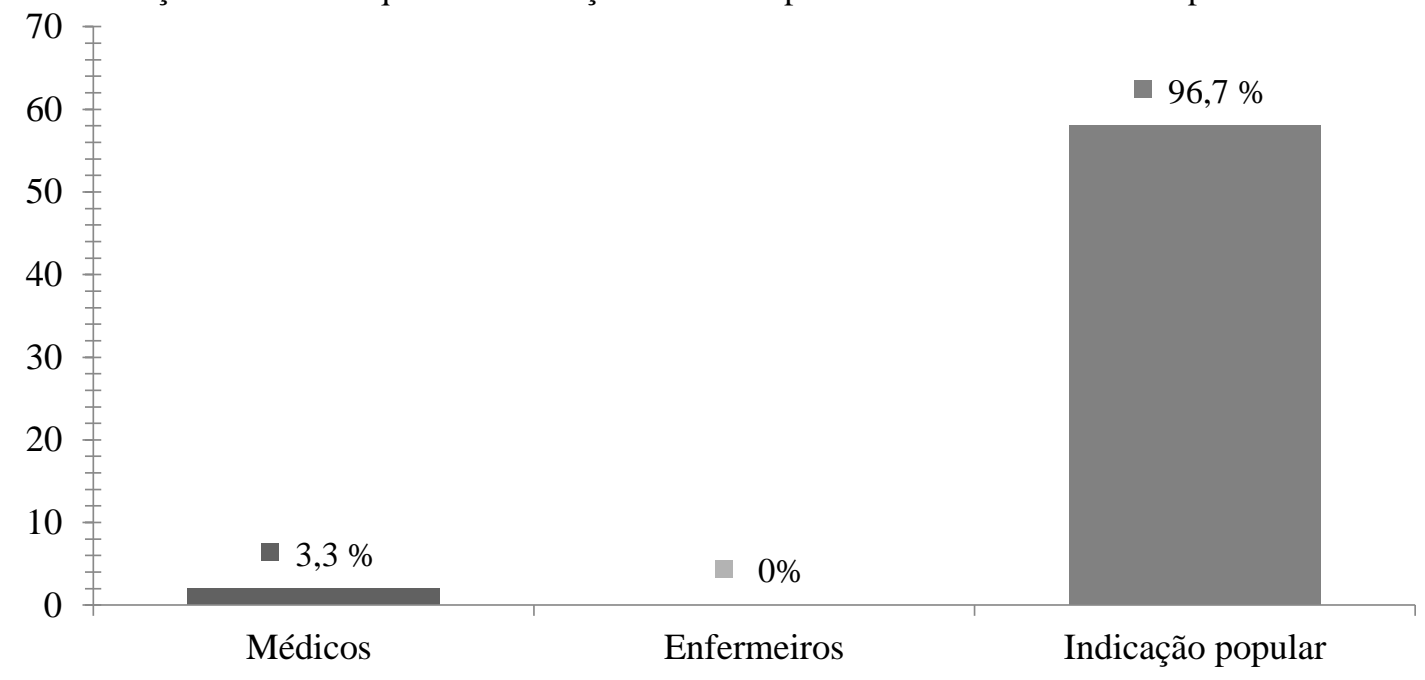

Na comparação entre a eficácia de medicamentos sintéticos e de ervas medicinais, foram observadas questões semelhantes em Paulínea SP, Queiroz, (1993), e em Niterói, RJ (TEIXEIRA e NOGUEIRA 2005). Os entrevistados em ambas as pesquisas afirmaram que a ação farmacológica dos medicamentos sintéticos é mais rápida que a das plantas. No estudo em Niterói os autores observam que no imaginário popular o medicamento é mais "forte" e eficaz para os casos mais graves, além de ser indicado por um representante da ciência; em contrapartida, a química presente, agride mais o organismo (TEIXEIRA, 2005). As ervas cujos efeitos seriam mais brandos, têm sua ação mais lenta. Diferentemente de Guizardi e Pinheiro (2008); Queiroz, (1993), afirma que em geral, a medicina caseira não contradiz nem se conflitua com a medicina oficial, na medida em que, na grande maioria dos casos ela não se coloca como alternativa, mas apenas como um complemento limitado.

De acordo com analise dos dados como mostra a Figura 4, onde de acordo com os usuários/pacientes, quando indagados se já tinham utilizado alguma planta medicinal no tratamento de doenças, entretanto, foram apresentados uma lista com 16 espécies medicinais, onde os mesmos indicavam quais já tinham sido usadas por eles, no entanto, os resultados demonstram que as espécies mais citadas foram as seguintes: Quebra pedra 58 citações, Hortelã 44, Aroeira 38, Babosa 32, Alecrim do nordeste 16 e unha de gato 10 citações essas foram as principais com o maior número de citações.

Figura 4 - Distribuição da amostra em relação às espécies utilizadas como medicamentosas citadas pelo usuários/pacientes

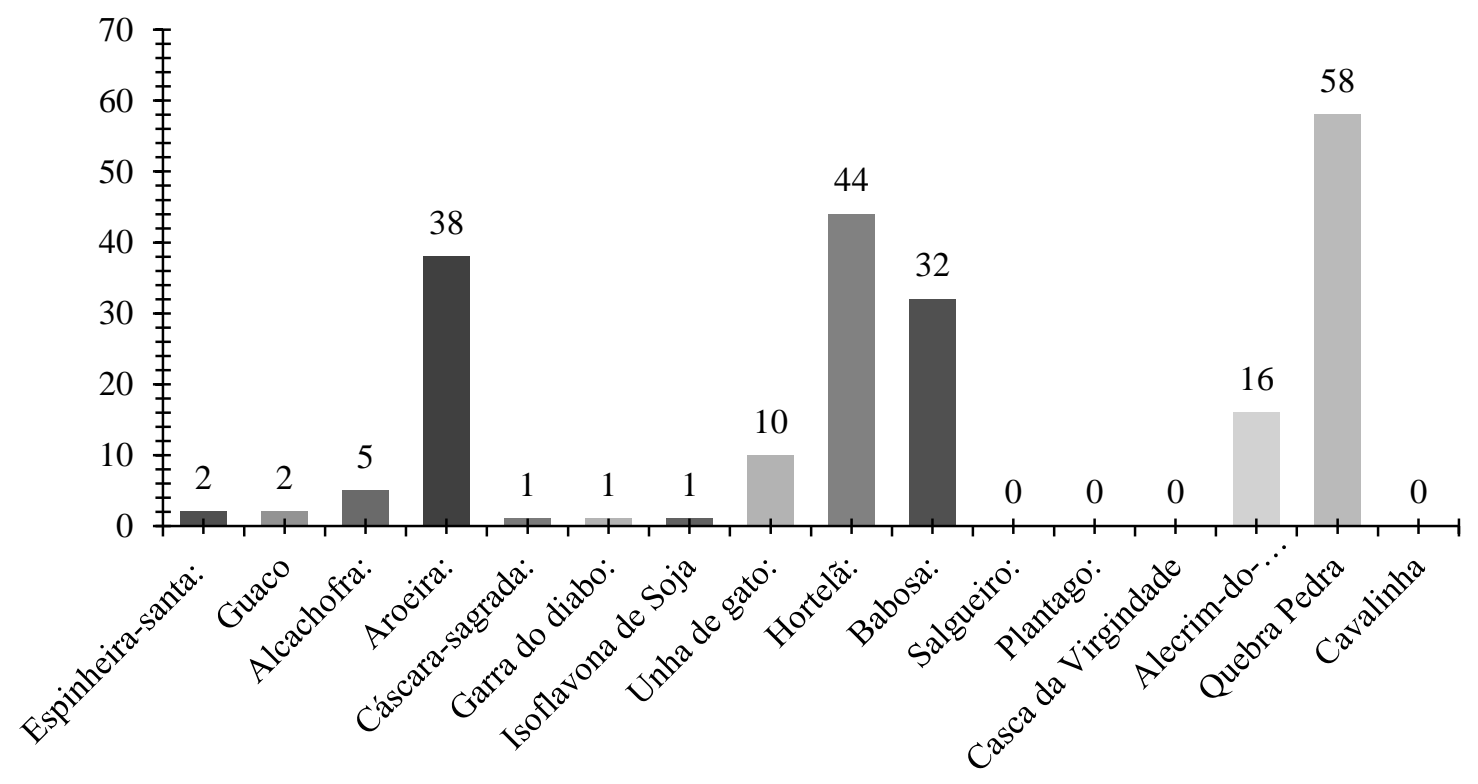


Comparando-se as espécies medicinais levantadas no presente estudo com as levantadas por Rodrigues (1998), Rodrigues et al. (2002) e Botrel et al., (2004), verificou-se que não existe semelhança entre os estudos. Algumas espécies citadas em quase todos os estudos realizados foram elas: Ruta glaveolens L. (Arruda), Cymbopogon citratus. Stapf (capim santo), Senna occidentalis L. (Link) (fedegoso), Punica granatum L. (romã) e a Tabebuia impetiginosa (Cham.) Standl. (Pau d'arco).

Em pesquisa realizada por Bandeira (2014) através de entrevistas com pessoas que fazem uso de plantas medicinais no tratamento de doenças em seres humanos as principais espécies citadas foram: alfazema (Lavandula spica Cav.), babosa (Aloe vera L.), boldo (Peumus boldus), cajueiro (Anacardium occidentale L.), capim santo (Cymbopogon citratus (DC) Stapf.), erva cidreira (Lippia alba (Mill.) N. E. Brown.), camomila (Matricária recutita), endro (Anethum graveolens), hortelã (Mentha sp.), jaramataia (Vitex gardneriana), macela (Egletes viscosa (L.) Less.), malva (Malva parviflora L.) e mastruz (Chenopodium ambrosoides L.).

De acordo com os dados obtidos na pesquisa, e quando os usuários/pacientes foram indagados sobre as possíveis reações adversas que os fitoterápicos ou plantas medicinais possam causar estão apresentados na figura 3, onde $(\mathrm{n}=50) 96,7 \%$ dos entrevistados afirmaram que durante o uso de fitoterápicos ou plantas medicinais não ocorreu nenhuma reação adversa, porem, $(n=2) 3,3 \%$ disseram já ter ocorrido alguma reação adversa ao uso de fitoterápicos ou uso de plantas medicinais.

A babosa (Aloe vera L.) tem ação cicatrizante, antibacteriana, antifúngica e antivirótica pela presença das antraquinonas como aloenina, barbaloína e isobarbaloína em sua composição química (MORAIS et al., 2005). Tais propriedades justificam seu uso popular, mas por causa da sua ação nefrotóxica em doses altas não deve ser usada por via oral, pois o teor de seu princípio predominante é aumentado e pode causar severa crise de nefrite aguda (MATOS, 2000).

Várias espécies de plantas têm sido utilizadas associadas in vitro a efeitos antiplaquetários. Esta propriedade tem sido utilizada como alternativa natural à aspirina; ginkgo (Ginkgo biloba L.), alho (Allium sativum L.) e gengibre (Zingiber offi cinale Roscoe), possuem este tipo de efeito (PINN, 2001, ERNST, 2003).
Figura 5 - Distribuição da amostra quanto às reações adversas ocorridas em função do uso de fitoterápicos ou plantas medicinais

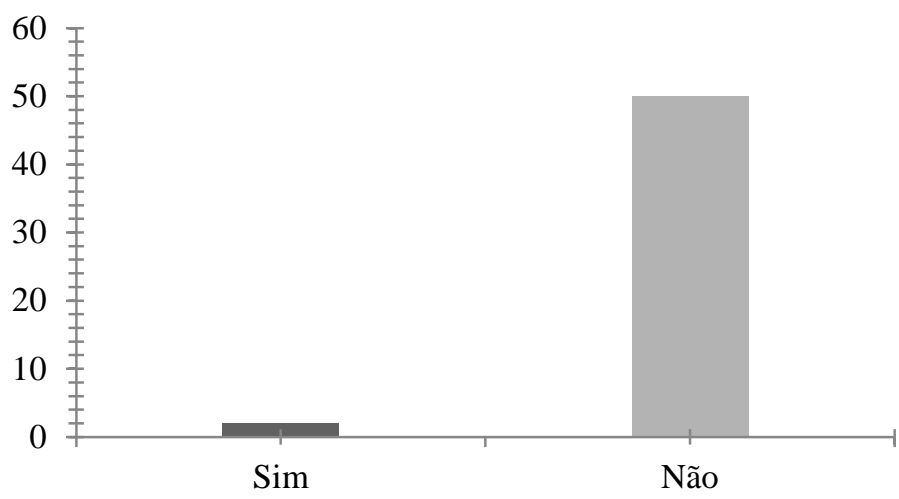

Bandeira (2014) analisando os dados coletados nos nove municípios, de forma conjunta, verifica-se que $93,24 \%$ dos entrevistados fazem uso de plantas medicinais no tratamento de doenças em seres humanos e que $62,16 \%$, nesse tipo de tratamento, costumam associar a planta medicinal ao mel de abelha. No que diz respeito à utilização de plantas medicinais no tratamento de doenças que acometem os animais, 57,72\% afirmaram que costumam utilizar tal forma de tratamento.

No que diz respeito à etnobotânica, um resultado aproximado foi encontrado por Teixeira e Melo (2006) quando da realização de uma pesquisa no sertão do Pajeú, no Pernambuco, onde ficou constatado que $100 \%$ dos entrevistados recorriam às plantas medicinais em casos de doenças.

De acordo com os dados mostrados na Figura 6 abaixo obtidos através das respostas dos usuários/pacientes entrevistados e indagados sobre o uso de plantas medicinais e se caso utilize onde elas são obtidas, os dados mostram que $46,7 \%$ responderam que adquirem as plantas em suas próprias hortas, $25 \%$ disseram que obtém as mesmas de produtores qualificados, 16,7\% adquirem de outras formas e 11,6\% responderam que adquirem de hortas comunitárias. Algumas respostas, a exemplo da aquisição de hortas comunitárias nos remetem a importância de trabalhos sociais, de pessoas organizadas em associações etc.

Figura 6- Distribuição da amostra com relação ao local onde as plantas medicinais são adquiridas

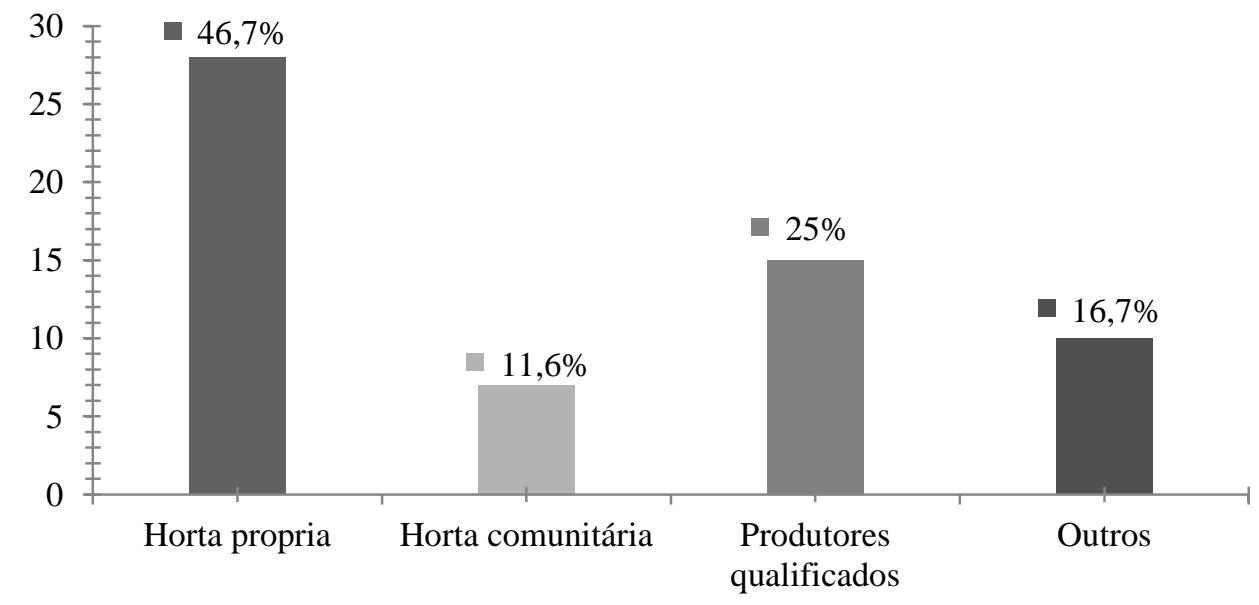


Em estudo realizado no município de Pombal, Andrade et al. (2012) demonstrou que 58,82\% dos entrevistados não plantavam as plantas que consumia como produto fitoterapeutico, o que uma situação inversa à revelada nesta pesquisa, visto que $46,6 \%$ dos entrevistados cultivam as espécies utilizadas no tratamento de doenças em seres humanos.

No entanto, esse percentual ficou baixo relacionado a um percentual encontrado por Melo Filho (2014), quando de um estudo realizado em Catolé do Rocha, também no sertão paraibano, demonstrando que $81,66 \%$ dos entrevistados cultivam as espécies vegetais que consumiam. Resultados que estão acima dos encontrados neste estudo.

Em pesquisa realizada por Dutra (2009) a autora revela uma preocupação com relação à forma de obtenção das plantas medicinais, $26,57 \%$ da população analisada lança mão do seu próprio domicílio, $17,61 \%$ dos vizinhos e $28,77 \%$ buscam no comércio as plantas que utilizam. Esse comércio inclui tanto as bancas localizadas em feiras livres e mercados municipais, quanto ambulantes instalados nas principais ruas da cidade de Anápolis. Um percentual ligeiramente inferior dos entrevistados $(27,05 \%)$ busca os preparados medicinais nas farmácias.

Marinho; Silva e Andrade (2011) mostram que em São José de Espinharas-PB, a população tem livre acesso às plantas medicinas, pois $54 \%$ dos entrevistados adquirem as plantas para consumo diretamente da mata ou cultivam em sua própria casa.

Analisando os dados obtidos na pesquisa mediante entrevistas com os usuários/pacientes pode-se observar na Figura 7 abaixo. Quando indagados sobre o que eles acham de uma farmácia de plantas medicinais e fitoterápicos do SUS disponível para a comunidade, $(\mathrm{n}=35) 58,4 \%$ responderam que é excelente, $(n=22) 36,6 \%$ disseram que é bom e $(n=3)$ $5 \%$ foram indiferentes, ou seja, não opinaram sobre o assunto.

Figura 7 - Distribuição da amostra quanto a implantação de farmácia de plantas medicinais ou fitoterápicos pelo SUS.

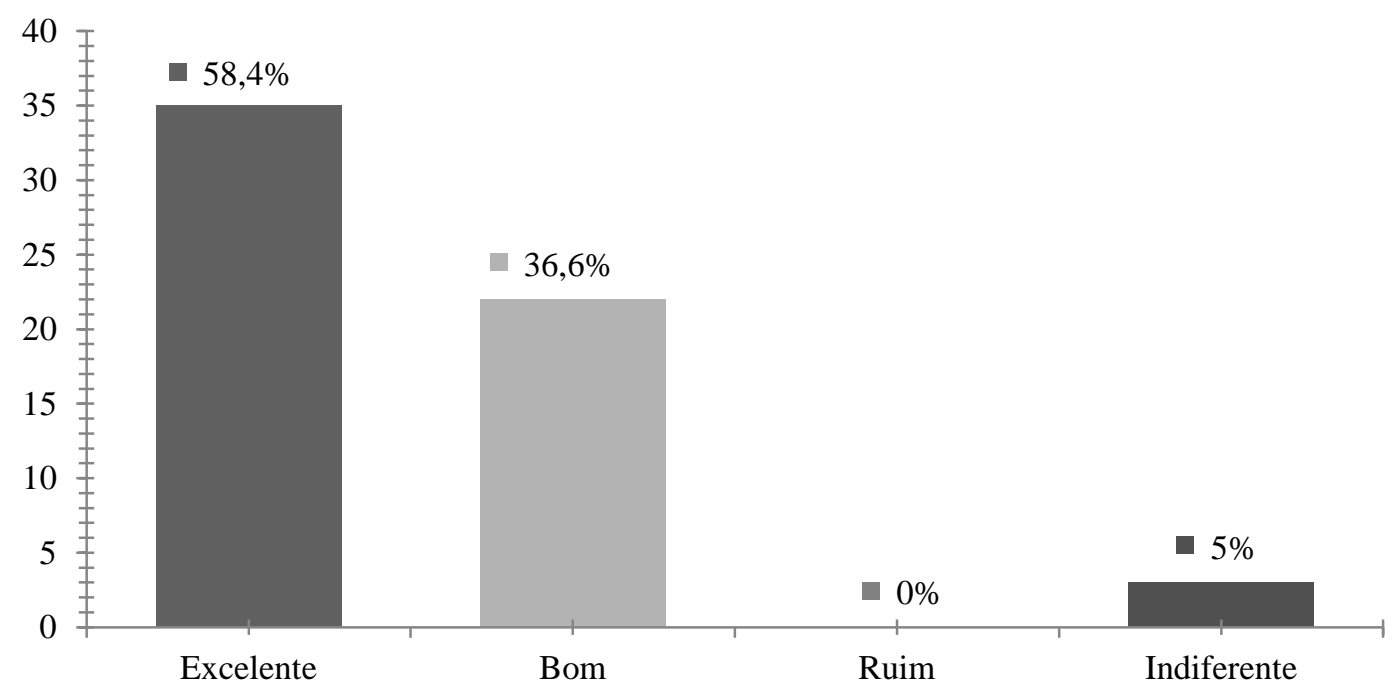

De acordo com os dados contidos na Figura 8 abaixo, onde os profissionais de saúde foram indagados se eles consideram inserção da fototerapia no SUS e principalmente nas UFS como avanço para a terapia comunitária, $(n=54) 90 \%$ dos entrevistaram responderam que $\operatorname{sim}$ e $(n=6) 10 \%$ disseram que não, esses dados demonstram que os profissionais de saúde são convictos de que a inserção dos fitoterápicos no SUS irá trazer benefícios a população.

Como apenas $10 \%$ dos entrevistados responderam que a inserção dos fitoterápicos no SUS não seria um avanço, isso pode ser reflexo do poderio econômico exercido pela grandes empresas fabricantes de medicamentos sintéticos que investem pesado tanto na produção de medicamentos, como também no marketing, fazendo com que alguns profissionais de saúde continuem prescrevendo apenas medicamentos sintéticos, aliado ao fato de que alguns profissionais nunca passaram por capacitação para prescrever medicamentos fitoterápicos.
Figura 8 - Inserção da fototerapia nos SUS e nas UFS.

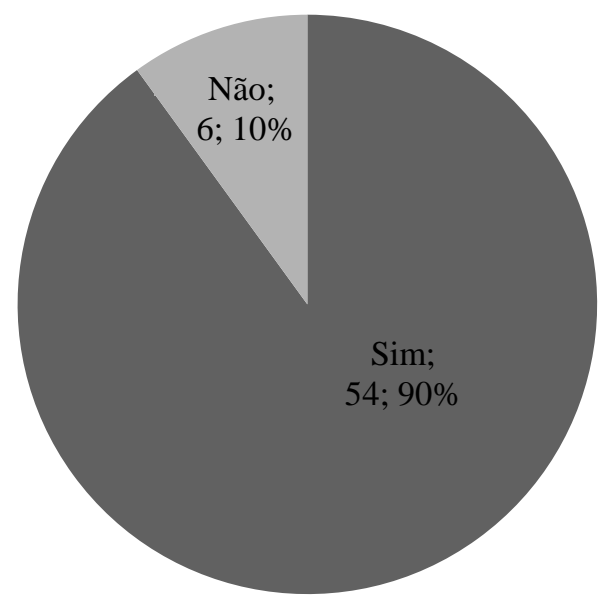

Silvello (2010) realizou um estudo sobre a utilização de plantas medicinais e fitoterápicos no Sistema Único de Saúde brasileiro, destacaram-se diversos aspectos positivos do uso de plantas medicinais e vantagens da inserção de fitoterápicos na rede pública de serviços de saúde, entre eles: o baixo custo, a menor incidência de efeitos colaterais, além 
da ampla aceitação por parte dos usuários, ressaltando também a importância da relação e aproximação entre o meio científico e o popular.

De acordo com um levantamento realizado pelo Ministério da Saúde, em 2004, em todos os municípios brasileiros, verificou-se que a fitoterapia está presente em 116 municípios, contemplando 22 unidades federadas. Foi observado que prefeituras que têm implantado programas de fitoterapia, aplicados nos serviços públicos de saúde, como são os casos de Vitória (ES), Curitiba (PR), cidade do Rio de Janeiro (RJ), Ribeirão Preto (SP) e Itapipoca (CE) revelam sua importância em termos de perspectiva de redução de custos com a saúde (ROSA, 2013)

No período de março a junho de 2004 o Ministério da Saúde (MS) realizou um levantamento junto as Secretarias de Saúde dos Estados e Municípios para obter informações a respeito de plantas medicinais e/ou fitoterapia. Foram enviados 5.560 questionários a todos os Secretários Estaduais e Municipais de Saúde. Retornaram 1342, dos quais 232 demonstraram alguma prática integrativa e/ou complementar em 26 estados. Foi constatado que somente $6 \%$ do total dispõem de regulamentação Estadual ou Municipal, criando serviços em práticas integrativas complementares no SUS e $35 \%$ dos municípios fornecia medicamentos fitoterápicos via farmácia pública de manipulação (BRASIL, 2006).

No que diz respeito aos profissionais de saúde com relação às crenças dos mesmos sobre seus conhecimentos sobre plantas medicinais e fitoterapia são suficientes para uma orientação e/ou prescrição adequada, os dados estão demonstrados na figura 9 , onde $(\mathrm{n}=53) 88 \%$ dos entrevistados disseram que não e apenas $(\mathrm{n}=7) 12 \%$ disseram que sim.

Figura 9 - Distribuição da amostra quanto ao fato dos profissionais de saúde acreditar que seus conhecimentos são suficientes para a prescrição de fitoterápicos.

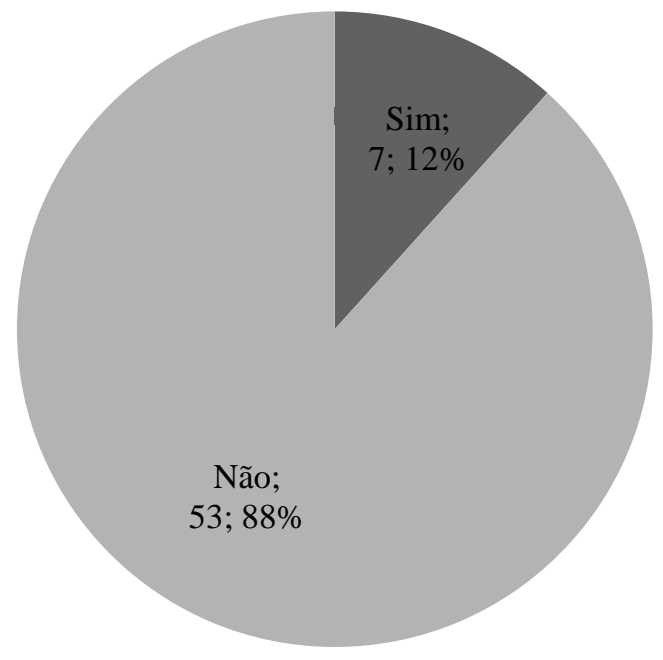

Entretanto, mesmo diante da prerrogativa dos SUS em inserir os fitoterápicos e plantas medicinais para prescrição pelos profissionais de saúde, segundo os dados obtidos na presente pesquisa um grande número entre os entrevistados, acham que os conhecimentos que possuem sobre o assunto é pouco, necessitando de investimentos em cursos de capacitações para que esses profissionais se sintam capacitados para prescreverem fitoterápicos.

Quanto aos recursos humanos, para atender a necessidade de promover capacitação técnica e educação permanente em plantas medicinais e fitoterápicos dos profissionais de saúde do SUS, foi incluída a Disciplina Gestão em Fitoterapia e Homeopatia, no Curso de Pósgraduação Lato sensu Gestão da Assistência Farmacêutica, financiado pelo MS, em 13 Instituições de Ensino Superior e Escolas de Saúde Pública (IES/ESP), para 440 farmacêuticos. Está em processo a contratação de parceria para realização de curso na modalidade de ensino à distância (EAD) em Fitoterapia para médicos no SUS. Também está prevista uma ação no Programa Mais Saúde, para capacitar profissionais de saúde e gestores em Plantas Medicinais /Fitoterapia, por meio de oficina para multiplicadores (NASCIMENTO JUNIOR et al., 2010).

Atualmente existe financiamento para oito fitoterápicos com recurso tripartite, ou seja, oriundo dos Municípios, Estados/DF e União. São eles: Cynara scolymus (Alcachofra), Glycine $\max$ (Soja - isoflavona), Harpagophythum procumbens (Garra-do-diabo), Rhamnus purshiana (Cáscara sagrada), Schinus terebinthifolius (Aroeira-da-praia), Uncaria tomentosa (Unha-de-gato), além de Maytenus ilicifolia (Espinheira-santa) e Mikania glomerata (Guaco), financiados desde 2007. Além de aumentar o número de fitoterápicos financiados, a Portaria GM/MS $\mathrm{n}^{\circ}$ 2.982/09 ampliou o valor do recurso que passou de $\mathrm{R} \$ 7,10$ para R\$ 8,82/hab/ano, assim distribuídos: União - $\mathrm{R} \$$ 5,10/hab/ano; Estados e Distrito Federal - R\$ 1,86/hab/ano; Municípios - R\$ 1,86/hab/ano.( BRASIL, 2009)

Quanto ao profissional enfermeiro são vários os aspectos que envolvem o uso de plantas medicinais na prática profissional da enfermagem. A aplicabilidade de terapias naturais por enfermeiros implica em aspectos éticos e legais, não possuindo força suficiente para ser tratada no plano da Lei do Exercício e do Código de Deontologia da profissão. Deste modo, não se torna possível sustentar mudanças que possam assegurar essa terapia como prática legítima da enfermagem, levando a história da enfermagem novamente para a luta pelo seu reconhecimento (PRÓ-REITORIA DE PESQUISA/UNESP, 2007).

De acordo com os dados apresentados na Figura 10, verifica-se que nas unidades de saúde em que os profissionais desempenham suas atividades existem varias espécies de plantas que são utilizadas pelos pacientes que procuram as unidades de saúde pesquisadas, no entanto, quando indagados sobre o uso das mesmas, eles responderam que fazem uso de Boldo $(\mathrm{n}=10)$, Hortelã e Erva doce $(\mathrm{n}=8)$, Eucalipto e Camomila $(n=7)$, Capim santo $(n=5)$, Macela e Quebra pedra $(n=4)$, as demais espécies citadas obtiveram uma quantidade menor de citações. 
Figura 10 - Distribuição da amostra quanto ao uso de plantas medicinais pelos pacientes atendidos nas unidades de saúde pesquisadas

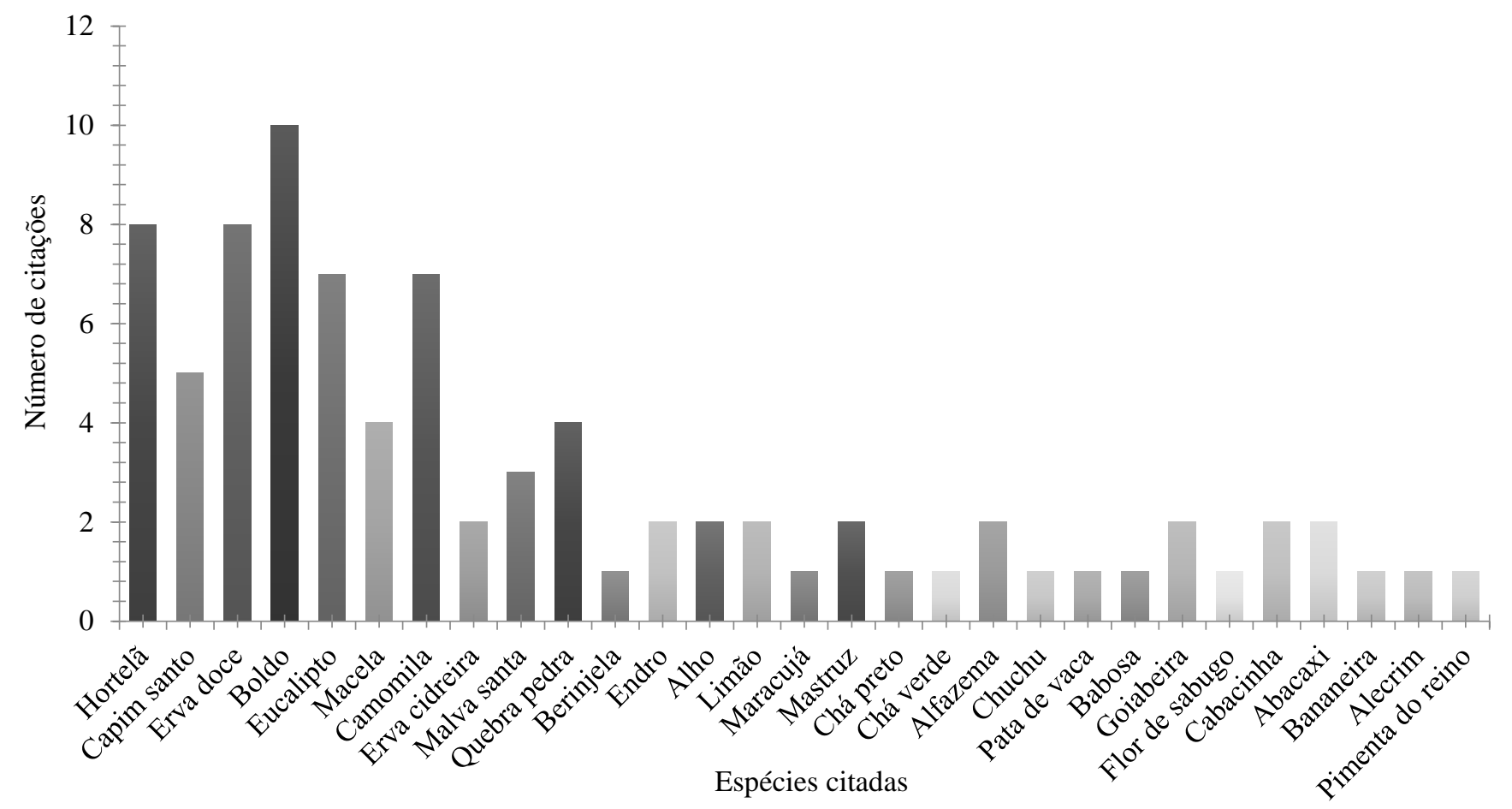

Bandeira (2014) em pesquisa realizada na região de Pombal PB, encontrou os seguintes resultados com relação ao uso de plantas medicinais no tratamento de doenças em seres humanos: alfazema (Lavandula spica Cav.), babosa (Aloe vera L.), boldo (Peumus boldus), cajueiro (Anacardium occidentale L.), capim santo (Cymbopogon citratus (DC) Stapf.), erva cidreira (Lippia alba (Mill.) N. E. Brown.), camomila (Matricária recutita), endro (Anethum graveolens), hortelã (Mentha sp.), jaramataia (Vitex gardneriana), macela (Egletes viscosa (L.) Less.), malva (Malva parviflora L.) e mastruz (Chenopodium ambrosoides L.). No entanto, as mais utilizadas foram: cidreira, macela, alfazema, capim santo, mastruz e hortelã, o que difere do presente pesquisa, isso pode ser justificada devido ao publico entrevistado ser bastante diferente.

Em outro trabalho Guerra et al., (2010) e estudo realizado no Assentamento Moacir Lucena, no município de Apodi-RN, revelou que as espécies mais citadas pelos entrevistados foram Anacardium Occidentale L. (cajueiro), Chenopodium ambrosoides L. (mastruz), Myracrodruon urundeuva (aroeira) e Ocimum basilicum L (manjericão). Dados, bem diferentes dos obtidos no presente estudo, que também cita o cajueiro e mastruz.

Em pesquisa realizada por Pontes et al., (2012) destacaram que no Nordeste brasileiro, com grande frequência, é comum o uso de plantas medicinais na preparação de remédios caseiros para o tratamento de doenças em seres humanos, com destaque para as seguintes espécies: hortelã; romã; melão de São Caetano Capim santo e ervacidreira, sendo que algumas das espécies citadas nesse trabalho coincidem com as encontradas na presente pesquisa.
$\mathrm{Na}$ Tabela 8 foram apresentados vários nomes de doenças que acometem as pessoas, no entanto, os profissionais de saúde foram fazendo suas ponderações sobre o assunto, sendo que o número de citações feitas foram as seguintes: Antidepressivos, calmante - Camomila, Maracujá, Erva cidreira $(\mathrm{n}=21)$, Tosse, gripe, sistema respiratório Abacaxi, Eucalipto, Limão, Alho, maracujá, Hortelã e Malva ( $\mathrm{n}=19$ ), Mal estar gástrico - Boldo, Macela, Sena, Camomila e Capim Santo $(n=14)$, Problemas geniturinário Quebra Pedra, Cana Mexicana $(\mathrm{n}=13)$, Problemas intestinais, diarreia - Goiabeira, Boldo, Capim Santo e Macela, ambos com $(\mathrm{n}=10)$, Emagrecimento - Sena, Chá Verde e Ibisco $(n=10)$, Hipertensão arterial sistêmica Chuchu e Endro $(n=9)$ e Problemas de pele $(n=9)$, os demais foram citados em menores quantidades.

De acordo com os dados apresentados as maiores frequiências encontrada foram para o antidepressivo calmante, com 0,35 , seguidos de tosse, gripe, sistema respiratório com 0,31 , mal estar gástrico com 0,23 e problema geniturinário com 0,21.

Em pesquisa realizada por Lima (2013) questionando sobre os motivos que os levavam a utilizar as plantas do cerrado para fins medicinais, e $90 \%$ dos assentados afirmaram que fazem uso freqüente devido ao conhecimento que já se tem sobre a eficiência dos remédios e chás caseiros, e que a distância da cidade não influencia em suas escolhas, apenas $10 \%$ optaram por irem logo ao posto de saúde ou à farmácia. Segundo Silva et al., (2010) o extenso uso de plantas medicinais também pode ser devido ao conhecimento e utilização de plantas representarem a única opção de tratamento de enfermidades, em razão do restrito acesso aos programas de saúde. 
Tabela 8 - Frequência da amostra quanto ao uso de fitoterápicos e suas recomendações pelos profissionais de saúde na atenção primária de saúde.

\begin{tabular}{|c|c|c|}
\hline Recomendações & Frequência & Espécies utilizadas \\
\hline $\begin{array}{l}\text { 1 - Antidepressivo, calmante } \\
\text { 2-Tosse, gripe, sistema respiratório } \\
\text { 3- Mal estar gástrico } \\
\text { 4-Problemas intestinais, diarreia. } \\
5 \text { - Emagrecimento } \\
\text { 6-Hipertensão arterial sistêmica } \\
7 \text { - Diabetes } \\
8 \text { - Problemas geniturinário } \\
9 \text { - Problemas de pele } \\
10 \text { - Menopausa } \\
11 \text {-Doenças infectocontagiosas e parasitárias } \\
\text { 12-Doenças osteomusculares } \\
\text { 13- Placebo }\end{array}$ & $\begin{array}{l}0,35 \\
0,31 \\
0,23 \\
0,16 \\
0,16 \\
0,15 \\
0,13 \\
0,21 \\
0,15 \\
0,016 \\
0,066 \\
0,050 \\
0,016\end{array}$ & $\begin{array}{l}\text { Camomila, Maracujá, Erva cidreira. } \\
\text { Abacaxi, Eucalipto, Limão, Alho, maracujá, } \\
\text { Hortelã e Malva. } \\
\text { Boldo, Macela, Sena, Camomila e Capim Santo. } \\
\text { Goiabeira, Boldo, Capim Santo e Macela. } \\
\text { Sena, Chá Verde e Ibisco. } \\
\text { Chuchu e Endro. } \\
\text { Pata de Vaca, Endro, Quiabo, Insulina e } \\
\text { Carambola. } \\
\text { Quebra Pedra, Cana Mexicana. } \\
\text { Babosa e Aroeira } \\
\text { Sena } \\
\text { Hortelã e Mastruz } \\
\text { Alho e Mastruz }\end{array}$ \\
\hline
\end{tabular}

Esse alto percentual de pessoas que utilizam as plantas do Cerrado apela para a necessidade de conservação dos remanescentes de cerrado que existem na área do assentamento, e incentivos, através de cursos de capacitação, para a disseminação do conhecimento tradicional e a troca de experiências entre os assentados. Para Silva et al., (2010) o uso de plantas no Brasil para fins medicinais é extenso, essas plantas são utilizadas até no combate e prevenção ao uso de drogas.
De acordo com os dados apresentados na Tabela 9, analisando a prescrição das diversas espécies apresentadas na tabela a seguir, observa-se uma baixa freqüência na indicação das mesmas por parte dos profissionais de saúde, onde Aloe Vera com uma freqüência 0,35, Rhamnus purshiana, Glycine max e Plantago ovata Forssk apresentaram de 0,033, Passiflora spp. 0,166 e Mentha x piperita com uma freqüência de 0,016 .

Tabela 9 - Distribuição da amostra quanto à denominação cientifica e popular de plantas medicinais indispensáveis na prescrição, seus usos e freqüência de indicação.

\begin{tabular}{|c|c|c|c|}
\hline Denominação cientifica & Denominação popular & Usos & Frequência \\
\hline 1 - Maytenus ilicifolia & Espinheira Santa & $\begin{array}{l}\text { azia, vômitos, digestão, } \\
\text { gastrite, úlcera }\end{array}$ & \\
\hline 2 - Mikania glomerata & Guaco & $\begin{array}{l}\text { Chá para reumatismos ou } \\
\text { inflamações }\end{array}$ & - \\
\hline 3 - Cynara scolymus & Alcachofra & Problemas hepáticos e renais & - \\
\hline 4-Schinus terebenthifolius & Aroeira vermelha & $\begin{array}{l}\text { É eficaz em micoses, } \\
\text { candidíasese alguns tipos de } \\
\text { câncer }\end{array}$ & - \\
\hline 5 - Rhamnus purshiana & Cascara sagrada & $\begin{array}{l}\text { prisão de ventre, possui efeito } \\
\text { laxante }\end{array}$ & 0,033 \\
\hline 6-Harpagophytum procumbens & Garra do Diabo & $\begin{array}{l}\text { anti-inflamatória, utilizada em } \\
\text { casos de reumatismos }\end{array}$ & - \\
\hline 7 - Glycine $\max$ & Soja & $\begin{array}{l}\text { Alívio dos } \begin{array}{l}\multicolumn{2}{c}{\text { sintomas }} \\
\text { relacionados à menopausa e } \\
\text { climatério }\end{array}\end{array}$ & 0,033 \\
\hline 8 - Uncaria tomentosa & Unha-de-gato & $\begin{array}{l}\text { antiinflamatório, } \\
\text { imunomodulador }\end{array}$ & - \\
\hline 9 - Mentha x piperita & Hortelã-pimenta & $\begin{array}{l}\text { aromaterapia para estimular os } \\
\text { sentidos, ajudar na digestão e } \\
\text { eliminar congestões }\end{array}$ & 0,016 \\
\hline 10 - Aloe Vera & Babosa & $\begin{array}{l}\text { Para o cabelo no tratamento da } \\
\text { seborréia ee também a ... fortes } \\
\text { diarréias }\end{array}$ & 0,35 \\
\hline 11 - Salix alba & Salgueiro-branco & $\begin{array}{l}\text { dores, febre e problemas } \\
\text { reumáticos }\end{array}$ & \\
\hline 12-Plantago ovata Forssk. & Psyllium casca & $\begin{array}{l}\text { tratamento de prisão ventre, } \\
\text { colesterol alto, excesso de } \\
\text { gases, diabetes tipo } 2\end{array}$ & 0,033 \\
\hline
\end{tabular}




\begin{tabular}{|c|c|c|c|}
\hline \multicolumn{4}{|l|}{ Continuação Tabela 9} \\
\hline Denominação cientifica & Denominação popular & Usos & Frequência \\
\hline 13-Anacardium occidentale & Cajueiro & $\begin{array}{l}\text { Òleo da casca da castanha, uso } \\
\text { externo: calos e verrugas, } \\
\text { dermatoses rebeldes }\end{array}$ & - \\
\hline $\begin{array}{l}\text { 14-Bauhinia sp }- \text { Bauhinia afinis, } \\
\text { Bauhinia forticata, Bauhinia variegata }\end{array}$ & Pata de vaca & Usado no controle do diabetes & - \\
\hline 15-Copifera spp. - Copaifera langsdorfil & Coopaíba & $\begin{array}{l}\text { Utilizada na forma de óleo para } \\
\text { tratar problemas de pele ou } \\
\text { artrite. }\end{array}$ & - \\
\hline 16 - Equisetum arvense & Cavalinha & $\begin{array}{l}\text { Osteoporose, } \\
\text { anemia, acido } \begin{array}{r}\text { úrico, } \\
\text { ansiedade, } \\
\text { arteriosclerose, } \\
\text { cálculos renais }\end{array} \\
\text { bexiga, }\end{array}$ & - \\
\hline 17 - Erythrina mulungu & Mulungu & $\begin{array}{l}\text { Antidepressivo, tranquilizante, } \\
\text { sedativo, }\end{array}$ & - \\
\hline 18 - Lippia sidoides & Alecrim-pimenta & Antisséptico e antimicrobiano & - \\
\hline 19 - Passiflora spp. & Maracujá & $\begin{array}{l}\text { Antidepressivos } \\
\text { tranquilizantes }\end{array}$ & 0,166 \\
\hline 20 - Phullantus spp. & Quebra-pedra & Usado nos tratamentos de rins & - \\
\hline 21-Solidago microglossa & Arnica-do-Brasil & & - \\
\hline 22-Stryphnodendron barbatiman & Barbatimão & $\begin{array}{l}\text { Adstringente e tônico, é usado } \\
\text { em inflamações do útero e } \\
\text { ovários, cicatrizante e para } \\
\text { lavagem íntima }\end{array}$ & - \\
\hline
\end{tabular}

Em relação aos médicos, quanto à utilização dos fitoterápicos, $17 \%$ ficaram a favor, enquanto $83 \%$ ficaram contra. Segundo Duniau (2003), muitos médicos têm feito severas críticas ao uso desta alternativa de tratamento, considerando-a "charlatanismo". Isso sem falar no perigo que algumas plantas apresentam em razão da toxidade e até na ocorrência de reações de dependência. $\mathrm{O}$ autor afirma que as duas posições estão erradas, em razão da ignorância sobre o assunto.

Em pesquisa realizada junto aos profissionais da rede municipal de saúde pela Secretaria Municipal de Saúde (SMS) de Vitória (ES), foi constatado que dos 44 médicos entrevistados, $61,3 \%$ tinha o interesse em prescrever medicamentos fitoterápicos aos seus pacientes. De posse dos dados da pesquisa, a Secretaria Municipal de Saúde implantou o Programa de Fitoterapia em Vitória (REVISTA BRASILEIRA SAÚDE DA FAMÍLIA, 2008).

Com relação aos profissionais de saúde entrevistados, tabela 11, quando indagados sobre a frequência com que você tem acompanhado pacientes com problemas relacionados ao uso de fitoterápicos ou reações adversas, $(n=$ 21) $35 \%$ disseram que nunca atenderam nenhuma ocorrência de pacientes com reações adversas ocasionadas pelo uso de fitoterápicos, porem, $(n=39) 65 \%$ responderam que atenderam, porém, com baixa frequência, isso demonstra que o uso de fitoterápicos tem baixa incidência de reações adversas e que as mesmas podem esta ligadas a fatores que não sejam ligados diretamente ao seu uso e sim a maneira como eles foram administrados por parte dos pacientes $p$ exemplo.
Figura 11 - Frequência do atendimento a pacientes com problemas relacionados ao uso de fitoterápicos

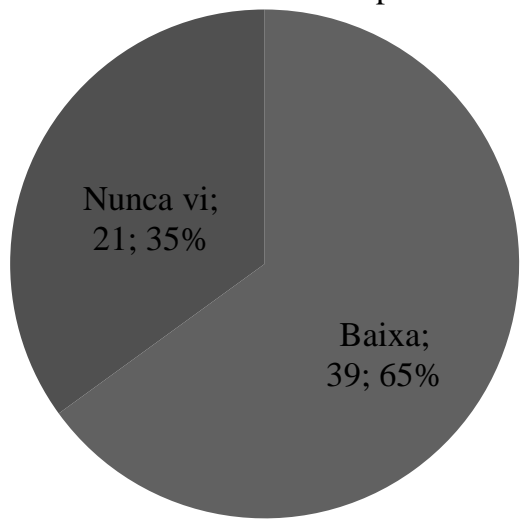

No que diz respeito ao fato dos profissionais de saúde terem passado por algum tipo de capacitação para indicação de fitoterápicos como método terapêutico, os dados da figura 12 abaixo mostram que $(\mathrm{n}=58) 97 \%$ dos profissionais de saúde entrevistados responderam que não e apenas $(n=2) 3 \%$ disseram já ter recebido algum tipo de capacitação para prescrever fitoterápicos como método terapêutico. Os dados revelam que a prescrição para a utilização de fitoterápicos por parte dos profissionais de saúde ainda é muito insipiente necessitando de mais incentivos e divulgação para o uso dos mesmos.

Ao se considerar a deficiência na formação acadêmica dos profissionais prescritores quanto ao emprego de plantas medicinal e fitoterápico como opção terapêutica, a existência de guia ou medicamento fitoterápico nos programas serve como facilitador da adesão desses profissionais, promovendo conhecimento científicotecnológico na área. Dos estados e municípios que participaram desse levantamento $26(72,2 \%)$ responderam positivamente, e cinco $(13,8 \%)$ informaram não possuir; dois 
municípios $(5,5 \%)$ informaram estar elaborando seus medicamentos e dois municípios $(5,5 \%)$ informaram trabalhar com protocolos de utilização (BRASIL, 2006).

Figura 12 - Profissionais de saúde que passaram por capacitação na indicação do uso de fitoterápicos.

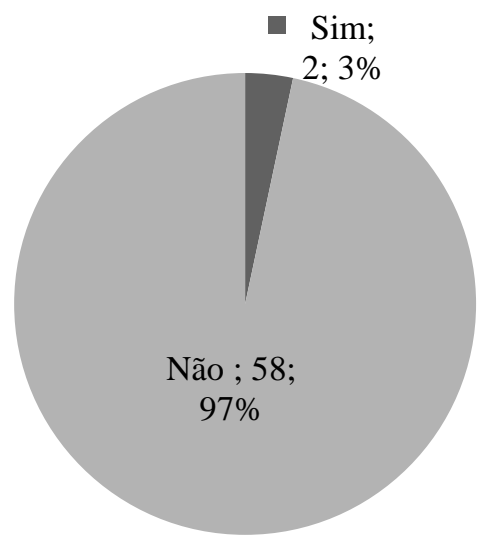

Embora a área de fitoterápicos esteja cada vez mais conhecida e desenvolvida, a disponibilidade de produtos fitoterápicos no mercado brasileiro ainda é bastante preocupante na visão do controle de qualidade desde a produção até a comercialização e uso pela população, pois a capacitação de profissionais nesta área ainda é escassa (CALIXTO, 2000).

A fitoterapia é considerada pela OMS uma prática da medicina tradicional (SIMON, 2001). Todavia, o uso deve ser precedido por criteriosa identificação e classificação botânica a fim de evitar a indução de erros e problemas durante a utilização. Muitas vezes os profissionais de saúde associam o uso destes medicamentos com os medicamentos alopáticos França et al., (2008), o que pode gerar riscos, uma vez que diversas interações têm sido descritas entre fitoterápicos e fármacos quimicamente definidos, algumas associadas à modulação da atividade enzimática no sítio de atuação (FRANCO, 2003).

\section{CONCLUSÕES}

Entre os usuários/pacientes pesquisados o uso de plantas para o tratamento de doenças é bastante elevado;

Ocorre uma baixa incidência de casos de usuários/pacientes com problemas relacionados ao uso de plantas medicinais;

Dos usuários/pacientes que fazem uso de plantas medicinais $46,7 \%$ cultivam as mesmas em hortas próprias;

As espécies de plantas mais utilizadas pelos pacientes que procuram as unidades de saúde, são Boldo, Hortelã e Erva doce;

Com relação à prescrição de fitoterápicos por parte dos profissionais de saúde a freqüência foi muito baixa, sendo o Aloe vera o de maior freqüência;

A maioria dos profissionais de saúde, cerca de $97 \%$ dos entrevistados nunca passou por capacitação para prescrever fitoterápicos;

Os usuários/pacientes relataram ser excelente a iniciativa de disponibilizar uma farmácia de plantas medicinais por parte do SUS;

\section{REFERÊNCIAS BIBLIOGRÁFICAS}

ANDRADE, S. E. O. et al., Estudo etnobotânico de plantas medicinais na comunidade Várzea Comprida dos Oliveiras, Pombal, Paraíba, Brasil. Revista Verde (Mossoró - RN), v. 7, n. 3, p. 46-52, jul-set, 2012

\section{BANDEIRA, A. S. ETNOCONHECIMENTO DA} UTILIZAÇÃO DE PLANTAS MEDICINAIS NA 14 REGIÃO ADMINISTRATIVA DA EMATER-PB. Dissertação (Mestrado em Sistemas Agroindustriais PPGSA). Pombal PB: UFCG, 2014, 60f.

BOTREL, R. T. et al. Espécies vegetais nativas usadas pela população local em Ingaí, MG. Lavras, MG: UFLA, 2004. 32p. (Boletim Agropecuário, 59).

BRASIL. Ministério da Saúde. Secretaria de Ciência, Tecnologia e Insumos Estratégicos. Departamento de Assistência Farmacêutica e Insumos Estratégicos. Programa Nacional de Plantas Medicinais e Fitoterápicos. Brasília: Ministério da Saúde, 2009.

BRASIL. Ministério da Saúde. Secretaria de Ciência, Tecnologia e Insumos Estratégicos. Departamento de Assistência Farmacêutica e Insumos Estratégicos. Política Nacional de Plantas Medicinais e Fitoterápicos. Brasília: Ministério da Saúde, 2006136 p.

BRASIL. Ministério da Saúde. Secretaria Executiva. Política Nacional de Medicina Natural e Práticas Complementares - PNMNPC. Brasília: SE/MS, 2005. $14 \mathrm{p}$.

CALIXTO, J. B. Effi cacy, safety, quality control, marketing and guidelines for herbal medicines (phytotherapeutics agents). Braz J Med Biol Res 33: 179-189. 2000.

DUNIAU, M. C. M. Plantas Medicinais: da magia à ciência. Rio de Janeiro: Brasport, 2003.

DUTRA, MARIA DA GLÓRIA. Plantas medicinais, fitoterápicos e saúde pública: um diagnóstico situacional em Anápolis, Goiás. (Dissertação de Mestrado) Programa de pós-graduação em Sociedade, Tecnologia e Meio Ambiente Centro Universitário de Anápolis - UniEvangélica, 2009. 112 f. : il.

Ernst. E. Serious psychiatric and neurological adverse effects of herbal medicines - a systematic review. Acta Psychiat Scand 108: 83-91, 2003.

FRANÇA, I. S. X. et al. Medicina popular: benefícios e malefícios das plantas medicinais. Revista Brasileira de Enfermagem, v.61, n.2, p. 201-8, 2008.

FRANCO, L. L. Doenças tratadas com plantas medicinais. 2.ed. Rio de Janeiro: Vozes, 2003.

GERMANO, F. N. et al., Alta prevalência de usuários que não retornam ao centro de testagem e aconselhamento (CTA) para o conhecimento do seu status sorológico Rio Grande, RS, Brasil. Ciência \& Saúde Coletiva, v. 13, n. 3, p. 1033-1040, 2008. 
GOMES, E. C. S. et al., PLANTAS DA CAATINGA DE USO TERAPÊUTICO: LEVANTAMENTO ETNOBOTÂNICOII Congresso de Pesquisa e Inovação da Rede Norte Nordeste de Educação Tecnológica João Pessoa - PB - 2007

GUERRA, A. M. N. et al. Utilização de plantas medicinais pela comunidade rural Moacir Lucena, Apodi-RN. Biosci. J., Uberlândia, v. 26, n. 3, p. 442-450, ma-jun., 2010.

GUIZARDI, F. L.; PINHEIRO, R. Novas práticas sociais na constituição do direito à saúde: a experiência de um movimento fitoterápico comunitário. Interface comun. saúde educ. [periódico na internet]. 12 (24): 109-22. 2008

HAMILTON, A. Medicinal plants and conservation: issues and approaches. International Plants Conservation Unit, WWF-UK, 2003.

IBGE. Enciclopédia dos Municípios Paraibanos - 2000..

IBIAPINA, W. V. et. al. INSERÇÃO DA FITOTERAPIA NA ATENÇÃO PRIMÁRIA AOS USUÁRIOS DO SUS. Rev. Ciênc. Saúde Nova Esperança -v. 2, n.1, p. 58-68, 2014.

IDEME. Anuário Estatístico da Paraíba versão 2000. João Pessoa, IDEME, 2000

LIMA, L. Fitoterápicos e usos de plantas medicinais. Jornal da UNESP, ano XVI, n. 166., 2006. Disponível em: http://www.unesp.br/aci/jornal/166/farmacologia.htm. Acesso: 5 nov 2013.

MACHADO, D. C, CZERMAINSKI, S. B. C, LOPES, E. C. Percepções de coordenadores de unidades de saúde sobre a fitoterapia e outras práticas integrativas e complementares. Saúde debate. [periódico na internet] 36(95):615-23. 2012.

MARINHO, M. G. V; SILVA, C. C; ANDRADE, L. H. C. Levantamento etnobotânico de plantas medicinais em área de caatinga no município de São José de Espinharas, Paraíba, Brasil. Rev. bras. plantas med. v. 13, n.2, p. 170-182, 2011.

MATOS, F. J. A. Plantas medicinais: guia de seleção e emprego de plantas usadas na fitoterapia no Nordeste do Brasil. 2. ed. Fortaleza: IU, 2000.

MELO FILHO, José Sebastião. O etnoconhecimento sobre plantas medicinais no município de Catolé do Rocha, Paraíba.Dissertação (Mestrado em Sistemas Agroindustriais). Universidade Federal de Campina Grande, Centro de Ciências e Tecnologia Agroalimentar. Pombal: UFCG, 2014.

MORAIS, I. C.; SILVA, L. D. G.; FERREIRA, H. D.; PAULA, J. R.; NASCIMENTO JÚNIOR, J. M.; COSTA, K. S.; TORRES, K. R.; ALVES, R. M. S.; Política Nacional de Medicamentos Fitoterápicos: desafios e perspectivas. Revista de Administração
Hospitalar e Inovação em Saúde, ano 2, no 4, p. 42-49, 2010.

MORAIS, I.C.; SILVA, L.D.G.; FERREIRA, H.D.; PAULA, J.R.; TRESVENZOL, L.M.F. Levantamento sobre plantas medicinais comercializadas em Goiânia: abordagempopular (raizeiros) e abordagem científica (levantamento bibliográfico). Revista Eletrônica de Farmácia, v. 2, n. 1, p. 13-16, 2005.

NASCIMENTO JÚNIOR, J. M.; COSTA, K. S.; TORRES, K. R.; ALVES, R. M. S.; Política Nacional de Medicamentos Fitoterápicos: desafios e perspectivas. Revista de Administração Hospitalar e Inovação em Saúde, ano 2, nº 4, p. 42-49, 2010.

PILlA, M. A. C.; AMOROZO, M. C. M.; FURLAN, A Obtenção e uso das plantas medicinais no distrito de Martim Francisco, Município de Mogi-Mirim, SP, Brasil. Acta bot. bras. [periódico na internet]. 20 (4): 789-802 2006.

Pinn, G. Adverse effects associated with herbal medicine. Australian Family Physician 30:1070-1075. 2001

PONTES, S. M. et al. Utilização de plantas medicinais potencialmente nocivas durante a gestação na cidade de Cuité-PB. Com. Ciências Saúde, v. 23, n. 23, n. 4, p. 305-311, 2012.

PRÓ-REITORIA DE PESQUISA/UNESP, 2007. Normas e Critérios sobre Fitoterápicos. Disponível em: $<$ http://www.ambientebrasil.com.br/composer.php3?bas $\mathrm{e}=$ /agropecuario/index.html\&conteudo=./agropecuario/arti gos/intro_fitot.html>. Acessado em: 05 jan. 2015.

QUEIROZ, M. S. Estratégias de consumo em saúde entre famílias trabalhadoras. Cad. Saúde Públ. [periódico na internet].v.9, n.3. p.272-82, 1993.

REUTERS. Brasil terá primeiro banco de dados de plantas medicinais. Folha Online, Brasil, 2002. Disponível em: $<\mathrm{http}: / /$

www.uol.com.br/folha/reuters/ult112u12329.shl>.

REVISTA BRASILEIRA SAÚDE DA FAMÍLIA. Ano IX. Edição Especial, mai. Brasília: Ministério da Saúde, 2008.

RICARDO, L. M. Uso de Plantas Medicinais: O Sistema Único de Saúde e a autonomia dos saberes comuns. Fundação Oswaldo Cruz. Especialização (Monografia) Escola Nacional de Saúde Pública Sérgio Arouca, 2009.

RODRIGUES, L. A. et al. Espécies vegetais nativas usadas pela população local em Luminárias, MG. Lavras: UFLA, 2002. 34 p. (Boletim Agropecuário, 52).

RODRIGUES, V. E. G. Levantamento florístico e etnobotânico de plantas medicinais dos cerrados na Região do Alto Rio Grande-Minas Gerais. 1998. 235 p. Dissertação (Mestrado em Engenharia Florestal). Universidade Federal de Lavras, Lavras-MG, 1998. 
ROSA, C.; CÂMARA, S. G.; BÉRIA, J. U. Representações e intenção de uso da fitoterapia na atenção básica à saúde. Ciênc. saúde coletiva [periódico na internet]. 2011 Jan [acesso em 2013 Jun 30]; 16(1): 311-18.

SILVA, J. S.; CARVALHO, J. N. F. de; TEIXEIRA, W. S.; FRANCO, I. O.; RIBEIRO, D. D. Importância do uso de plantas medicinais em comunidades rurais no sudoeste de Goiás. In: Cadernos de Agroecologia, vol. 5, n.1, 2010, p. 1-4.

SILVELlO, C. L. C. O uso de plantas medicinais e de fitoterápicos no SUS: uma revisão bibliográfica: [Trabalho de conclusão de curso]. Porto Alegre: Universidade Federal do Rio Grande do Sul, 2010.

SIMON, D. R.; CHOPRA, D. O guia Deepak Chopra de ervas: 40 receitas naturais para uma saúde perfeita. 1.ed. Rio de Janeiro: Campus, 2001. 272p.

SOUZA, C. M. P.; BRANDÃO, D. O.; SILVA, M. S. P.; PALMEIRA, A. C.; SIMÕES, M. O. S.; MEDEIROS, A. C. D. Utilização de plantas medicinais com atividade antimicrobiana por usuários do serviço público de saúde em Campina Grande - Paraíba. Rev. bras. plantas med. 29; 15(2):188-93. 2013.

TEIXEIRA E. R.; NOGUEIRA, J. F. O uso popular das ervas terapêuticas no cuidado com o corpo. Rev. Gaúcha Enferm [periódico na internet]. 2005 [acesso em $12 \mathrm{dez}$ 2008]; 26 (2): 231-41.

TEIXEIRA, S. T.; MELO J. I. M. Plantas medicinais utilizadas no município de Jupi, Pernambuco, Brasil. Iheringia, Ser. Bot., v. 61, n. 1-2, 2006

TRESVENZOL, L. M. F. Levantamento sobre plantas medicinais comercializadas em Goiânia: abordagem popular (raizeiros) e abordagem científica (levantamento bibliográfico). Revista Eletrônica de Farmácia, v. 2, n. 1, p. 13-16, 2005. 